\title{
AVANÇOS LOGÍSTICOS NO VAREIO NACIONAL: O CASO DAS REDES DE FARMÁCIAS
}

Claude Machline Professor Titular do Departamento de Administração da Produção e de Operações Industriais da EAESP/FGV e Professor Emérito da EAESP/FGV.

José Bento C. Amaral Júnior Professor Titular do Departamento de Administração da Produção e de Operações Industriais da EAESP/FGV e Consultor de Empresas pelo GVconsult/EAESP/FGV.

RESUMO: O artigo descreve as conquistas realizadas na logística do varejo farmacêutico nacional nos últimos anos. As farmácias organizaram-se em redes; melhoraram seu aspecto visual; muitas operam 24 horas; usam fórmulas sofisticadas, teoricamente corretas, na gestão de estoques; dispõem de softwares avançados; operam depósitos racionalizados, por vezes automatizados; as entregas às lojas são diárias; o código de barras facilita o controle dos produtos. Subsistem problemas que impedem a obtenção de autêntico just in time e de falta-zero: dificuldade de prever a demanda; limitação da capacidade dos bancos de dados para registrar dados relativos a 5.000 apresentações em 100 lojas; entrosamento precário entre os setores de vendas e compras na empresa; freqüência e rapidez ainda insuficientes de reposição dos produtos no depósito e nas lojas; existência de numerosos medicamentos de baixo giro. Recomendações são apresentadas para a remoção desses entraves e o advento do sonhado Supply Chain Management.

ABSTRACT: This paper describes recent logistics developments observed in retail operations of pharmaceutical products in Brazil. Most pharmacies restructured themselves in chains. They improved their physical appearance. Some operate full-time. They rely upon advanced software and use refined formulas, based upon the best theory, to manage inventories. The central storage areas are well administered; a couple of them are automated; deliveries to stores are made daily; bar coding helps controlling product flow. A score of problems still hampers the obtainment of an authentic just in time result and a real zero-shortage situation: data bases lack capacity to register all the necessary information concerning 5,000 different items in 100 outlets; barriers persist between sales and purchasing departments; deliveries by suppliers to the central store are not as frequent and quick as desirable, so are deliveries to retail stores; harmful to efficiency is the presence of quite a number of low turnover, slow moving medicaments. Recommendations are offered in order to foster the still remote implementation of the dreamed Supply Chain Management.

PALAVRAS-CHAVE: logística, distribuição de medicamentos, varejo farmacêutico nacional, cadeia de suprimentos, redes de farmácias, Supply Chain Management.

KEY WORDS: logistics, distribution of pharmaceutical products, Brazilian drug retailing, drugstore chains, Supply Chain Management. 
Numerosas empresas nacionais de varejo têm efetuado nos últimos anos apreciáveis avanços na área logística. Novas técnicas de gestão de estoques, automação do depósito, computação e telecomunicações vêm sendo usadas como resposta à competição acirrada que determina, por seleção natural, as empresas que sobreviverão. É objetivo deste trabalho relatar algumas realizações que os autores, por força de sua participação em projetos de consultoria, tiveram ocasião de presenciar na logística de varejo. $\mathrm{O}$ artigo trata especificamente da distribuição de medicamentos na rede farmacêutica. Espera-se contribuir para a divulgação de "boas técnicas logísticas" aplicadas ao comércio nacional e debater problemas que continuam constituindo desafios à obtenção de serviços mais eficientes e de melhor qualidade.

\section{PANORAMA ATUAL DO VAREJO FARMACÊUTICO}

Os clientes não podem ter deixado de perceber as alterações recentes ocorridas no comércio farmacêutico. Uma constatação óbvia é a formação de numerosas redes de farmácias, que deixaram de ser lojas isoladas. A população notou também que algumas farmácias permanecem abertas 24 horas; muitas ostentam requintes de elegância; o arranjo físico se afasta do que dominava nas antigas "pharmácias" e boticas: os medicamentos são dispostos de forma compacta em prateleiras abertas, no fundo e nas laterais, enquanto o centro da loja está repleto de gôndolas de cosméticos e artigos de higiene pessoal. À semelhança dos supermercados, o caixa é computadorizado. Além das melhorias que saltam aos olhos, outras proezas de automação comercial ocorrem atrás da cortina: um software liga o caixa ao computador central da rede, atualizando o faturamento e o estoque, em tempo real, sempre que entra ou sai mercadoria da loja.

\section{A CADEIA DE SUPRIMENTOS}

A Figura 1 representa a cadeia de suprimentos, que se estende desde os fornecedores de matérias-primas (fármacos) até o consumidor final, passando pelos fabricantes (laboratórios), que entregam medicamentos diretamente às redes ou, indiretamente, por meio de distribuidores. O segmento institucional (hospitais, centros de saúde, secretarias públicas estaduais e municipais de saúde), ao lado das farmácias, constitui importante mercado. As farmácias compram também produtos de higiene pessoal e cosméticos, em geral, diretamente dos fabricantes.

Os fabricantes e distribuidores entregam os medicamentos ao depósito central da rede, que estoca os produtos e os aloca às lojas. A

Figura 1 - Cadeia de suprimentos da área farmacêutica

* Este trabalho foi apresentado no I SIMPOI
- Simpósio de Administração da Produção,
Logística e Operações Industriais, realizado
na EAESP/FGV, em setembro de 1998.

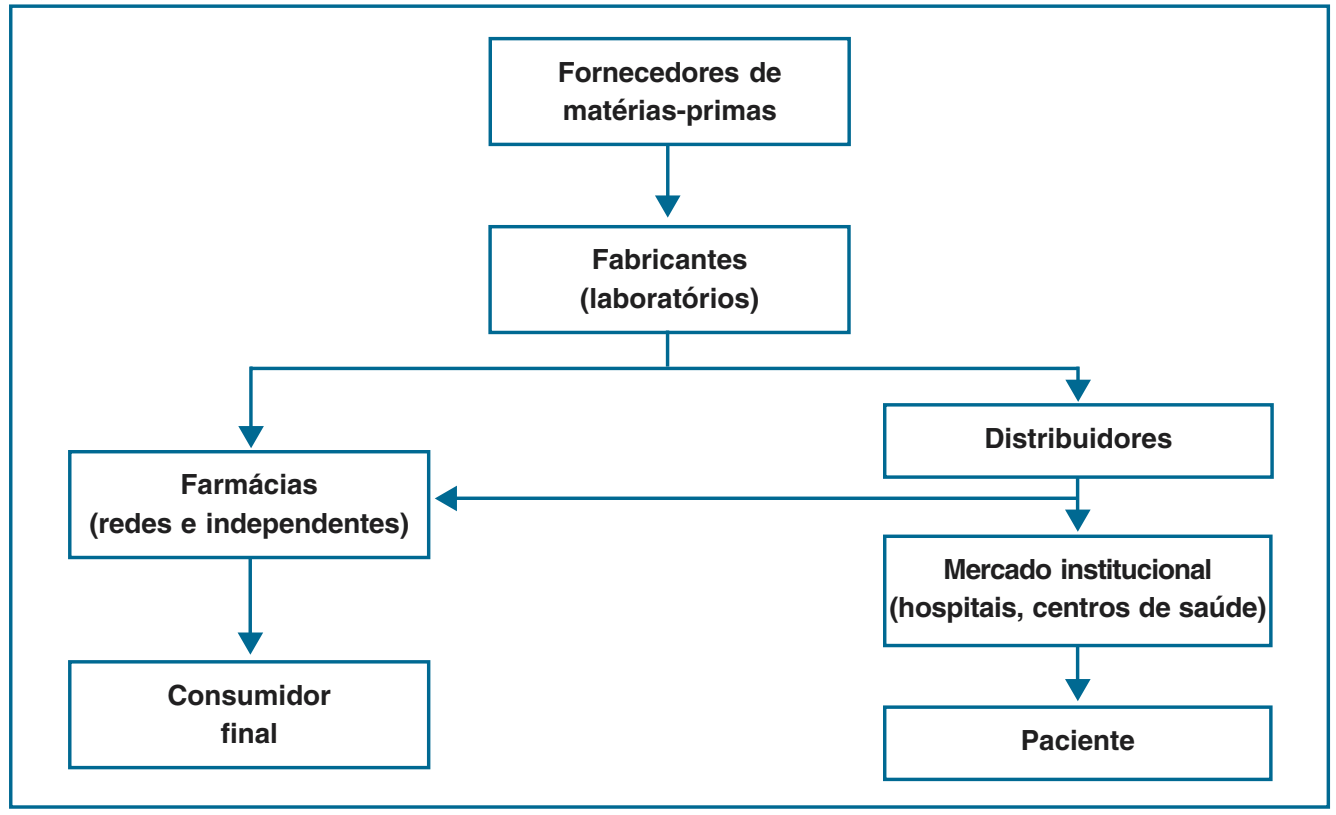


Figura 2 representa a cadeia logística que prevalece no setor farmacêutico.

Figura 2 - Cadeia logística na rede farmacêutica

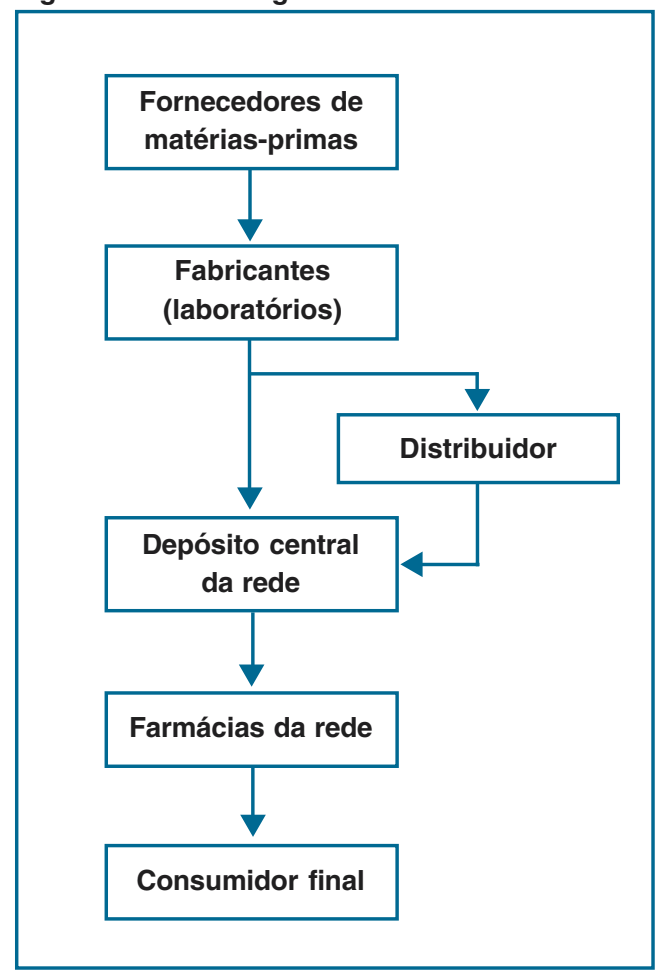

A margem de contribuição da cadeia, do laboratório até o consumidor final, é de $30 \%$. O distribuidor, dentro desses $30 \%$, opera com margem de $14,62 \%$, e a farmácia, com $18,0 \%$. O mercado institucional é abastecido com produtos de uso restrito a hospitais, entregues em embalagens hospitalares.

Compra de distribuidores constitui a principal opção para as farmácias independentes, que não movimentam o volume mínimo necessário para aquisição direta do fabricante. O prazo de entrega do fabricante é de dois a cinco dias úteis, enquanto o do distribuidor é de um a dois dias. O distribuidor entrega uma gama de milhares de apresentações, enquanto cada laboratório produz e distribui menos de 100 itens.

\section{LOGÍSTICA DA ÁREA FARMACÊUTICA}

Definições tradicionais de logística encontram-se em Ballou ${ }^{1}$ e Novaes \& Alvarenga. ${ }^{2}$ Os avanços indicados pertencem ao estrito campo da logística ou constituem algo mais?
Em 1986, o Council of Logistics Management (CLM) definiu logística da seguinte forma: "é o processo de planejamento, implementação e controle do fluxo eficiente e eficaz de matérias-primas, estoques de produtos semi-acabados e acabados, bem como de fluxos de informações a eles relativo, desde a origem até o consumo, com o propósito de atender aos requisitos dos clientes". ${ }^{3}$

À medida que as empresas integram seus esforços para oferecer aos clientes mais que a entrega da mercadoria no local e na hora certos, pode-se falar de Supply Chain Management (SCM), definido, pelo International Center of Competitive Excellence, em 1994, como sendo: “(...) a integração dos processos do negócio desde o usuário final até os fornecedores originais que proporcionam os produtos, serviços e informações, a fim de agregar valor para o cliente". "Definições semelhantes encontram-se em Johnson ${ }^{5}$ e Saunders. ${ }^{6}$ Embora, hoje, o esforço cooperativo dos membros da cadeia seja diminuto, ele se faz sentir nas áreas de promoção de vendas e de lançamento de novos produtos, momentos esses em que o entrosamento entre fabricante e rede é indispensável - e, nesses casos, pode-se identificar, ainda que restrito, um procedimento integrado, que é a chave do SCM.

O Efficient Consumer Response (ECR), conceito recém-lançado e atualmente em voga, confere, como o SCM, primazia ao trabalho conjunto dos parceiros, em vez de eles se dedicarem a empreender ações isoladas ou até antagônicas.?

Nas ações típicas de ECR inserem-se as seguintes iniciativas:

- gerenciamento de categorias: integração de fornecedores e varejistas na definição de uma estratégia comum para o desenvolvimento mercadológico de uma linha de produtos;

- gestão partilhada da demanda e reposição automática do produto no ponto-devenda, a partir de informações fornecidas pela loja, por meio de EDI (Electronic Data Interchange - Intercâmbio Eletrônico de Dados);

- paletização padronizada da carga.

Uma dificuldade invocada pelas redes farmacêuticas para justificar a falta de maior entrosamento com os fornecedores é a pulverização do mercado de medicamentos. Na indústria e no varejo farmacêuticos, as fati-
1. BALLOU, Ronald H. Logística empresarial, transporte, administração de materiais, distribuição física. Traduzido por Hugo T. Y. Yoshizaki da $2 \underline{a}$ ed. de Basic business logistics, 1987. São Paulo: Atlas, 1993. p.17.

2. NOVAES, Antônio Galvão N., ALVARENGA, Antônio Carlos. Logística aplicada, suprimento e distribuição. São Paulo: Pioneira, 1994. p.64.

3. COOPER, Martha C., LAMBERT, Douglas M., PAGH, Janus D. Supply Chain Management: mais do que um novo nome para a Logística, Parte I. Traduzido do The International Journal of Logistics Management, Logística Moderna, n.54, jan.-fev. 1998, p.17-20.

4. Idem, ibidem.

5. JOHNSON, G., SCHOLES, K. Exploring corporate strategy. text and cases. 3.ed. Englewood Cliffs, N. J.: Prentice-Hall, 1993. p.30.

6. SAUNDERS, Malcolm. Strategic Purchasing and Supply Chain Management. London: Pitman Publishing, 1994. p.107.

7. ECR: os primeiros resultados, Logistiques Magazine, maio 1997. Reproduzido em Logística Moderna, n.17, jan.-fev. 1998, p.6-12. 
as de mercado de cada empresa não passam de $5 \%$. Nem a febre de macrofusões que atingiu o mercado farmacêutico chegou a alterar essa fragmentação. Ao contrário do que ocorre no segmento de supermercados, nenhuma empresa industrial ou comercial é forte o bastante no ramo para exercer liderança sobre seus fornecedores ou clientes e armar uma vigorosa cadeia de suprimentos.

\section{PROGRESSOS REALIZADOS}

Os progressos mais significativos obtidos na distribuição de produtos farmacêuticos no País foram realizados ao longo de quatro dimensões:

\section{Gestão racional de estoques}

Foram instalados nas redes sistemas avançados de gestão de estoques, baseados em fórmulas clássicas, teoricamente corretas sob o ponto de vista estatístico.

Recorre-se geralmente ao sistema denominado de "revisão periódica", que permite encomendar, num mesmo pedido, toda a lista de produtos de um fabricante.

Os pedidos que, anos atrás, eram colocados mensalmente, o são agora semanal ou bissemanalmente, o que reduz em $75 \%$ ou $87,5 \%$ o estoque operacional do depósito central.

O estoque de segurança do depósito é calculado cientificamente, baseando-se em da- dos quantitativos referentes ao atraso possível de entrega do fornecedor e ao aumento da demanda em relação à demanda média.

O reabastecimento é efetuado visando a atingir um nível desejado do estoque, denominado estoque máximo, cujo cálculo leva em conta o intervalo entre revisões periódicas e o prazo de entrega.

Como previsão da demanda toma-se a média de venda do produto nos três meses anteriores. É ajustada por um fator que permite considerar a influência de efeitos sazonais.

O sistema depósito-lojas possui dois estágios de estoque, o que aumenta a complexidade dos cálculos. Em cada loja existem um estoque de segurança e um estoque máximo, cujos valores são computados por meio de fórmulas semelhantes às empregadas para o depósito central.

Os distribuidores, por sua vez, utilizam fórmulas similares para gerir seus estoques.

A Figura 3 representa esquematicamente os principais elementos do sistema de revisão periódica do depósito central e de uma loja.

\section{Uso de softwares de gestão de estoques}

As redes de farmácias usam intensamente softwares de gestão de estoques, desenvolvidos por seus setores de informática, por empresas especializadas ou ainda adaptados de programas comerciais. As primeiras ge-

Figura 3 - Sistema de revisão periódica no depósito central e na loja

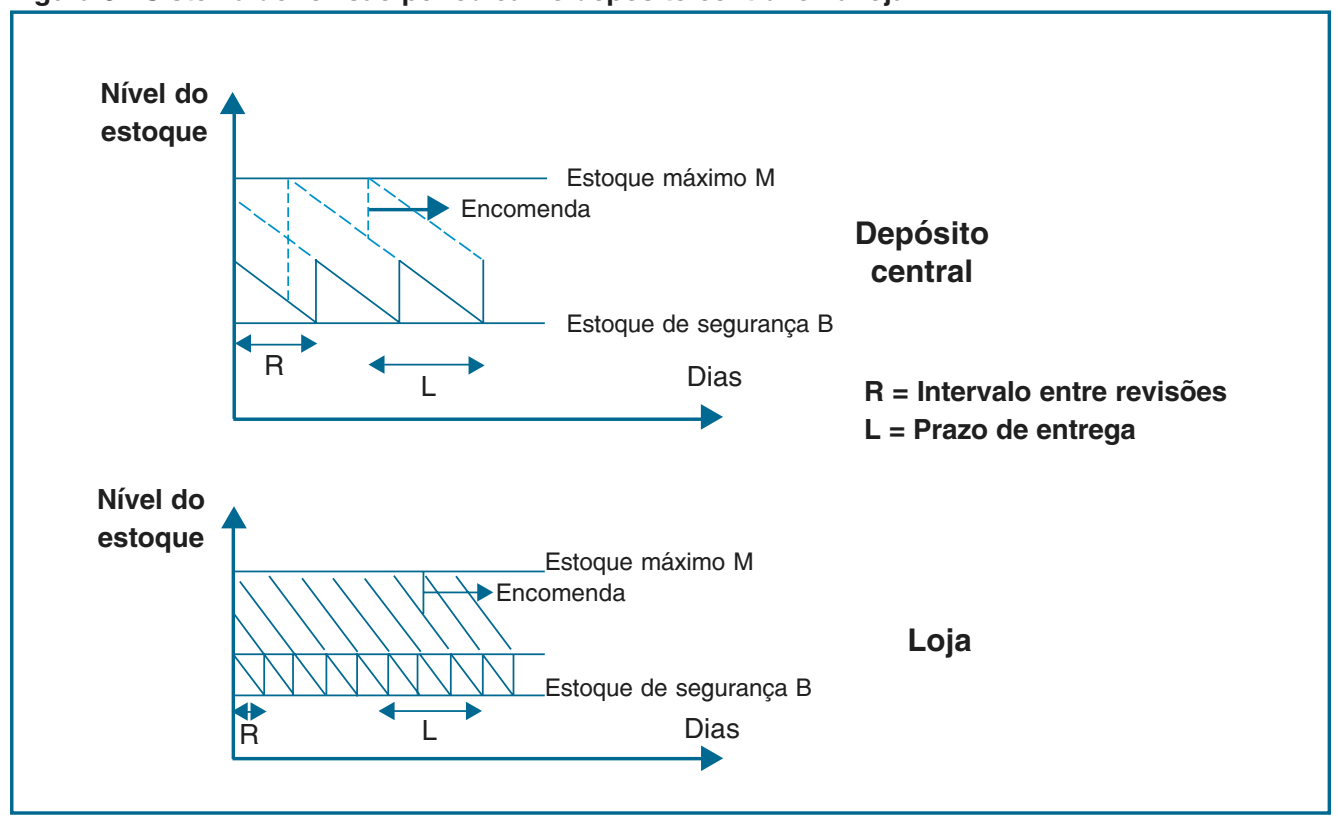


rações desses sistemas eram baseadas em computadores centrais. Foram em sua maioria convertidas para operar em microcomputadores ligados em rede. Todas as farmácias são ligadas ao servidor central por teleprocessamento. Os bancos de dados devem possuir considerável capacidade para armazenar na memória informações relativas a uma dezena de parâmetros de gestão, em centenas de farmácias, para milhares de produtos, dos quais é preciso conhecer as vendas e os estoques, dia a dia, durante os 12 meses anteriores.

\section{Racionalização das operações do depósito central}

Os depósitos centrais das redes de farmácias e das distribuidoras operam há anos com arranjo físico racional, instalações adequadas e equipamentos modernos de transporte interno, objetivando rapidez, qualidade e minimização dos custos.

As funções básicas são o recebimento dos engradados dos fornecedores, a separação dos pedidos destinados às lojas (picking), a expedição e o transporte das mercadorias às farmácias.

O picking é efetuado de acordo com o princípio de uma linha de montagem. Um contentor vazio é colocado na extremidade de uma esteira rolante, ao longo da qual operadores, consultando listas de separação, retiram os itens de prateleiras dispostas de um lado a outro da esteira. No outro extremo da correia transportadora, o contentor, preenchido com os itens destinados à loja específica, é removido e transferido por outra esteira, em direção à área de expedição; nesta, os contentores são agrupados por lojas, em boxes numerados, carregados em veículos (caminhonetes ou peruas) e transportados às lojas, nas quais as mercadorias são conferidas e dispostas nas prateleiras.

Certos depósitos contam com um sistema de picking automatizado. Embora o investimento inicial seja da ordem de um milhão de dólares, estima-se que seu tempo de recuperação seja de menos de um ano, por força das economias de pessoal proporcionadas pela automação, bem como pela redução do tempo de ciclo e a eliminação de erros.

O funcionamento eficiente do depósito requer a capacidade de processar e transmitir instantaneamente informações relativas a entra- das e saídas de mercadorias e emitir documentos tais como listas de separação, romaneios, notas fiscais de entrega às lojas, etiquetas de identificação dos produtos e outros.

Duas técnicas próprias da indústria farmacêutica - a numeração dos lotes e a codificação de barras - têm facultado a rastreabilidade de cada item e facilitado o controle dos estoques ao longo da cadeia de operações.

\section{Entregas às lojas}

A quarta vertente de progressos situa-se na entrega às lojas. Os maiores desafios consistem na utilização plena de carga dos veículos, na sua roteirização, na administração da frota e dos motoristas, para a qual existe a opção de terceirização, e, acima de tudo, na batalha contínua contra o congestionamento de trânsito, as restrições à circulação e ao estacionamento das viaturas. Parcela considerável da luta logística é travada à noite e passa despercebida, mas, sem o sacrifício do pessoal, em geral mal reconhecido, não se pode pretender a entrega dos produtos certos na hora e na loja certas, todos os dias do ano, que é a condição básica para se ganhar o cobiçado prêmio representado pelo just in time.

\section{PROBLEMAS REMANESCENTES E RECOMENDAÇÕES}

Listam-se a seguir os obstáculos que têm sido observados com maior frequiência nas operações logísticas das redes farmacêuticas. Recomendações são apresentadas.

\section{Previsão da demanda}

É difícil prever a demanda de milhares de itens, um a um. Para a maioria dos produtos, farmacêuticos e cosméticos, o método preferido pelas redes consiste em utilizar, como demanda diária do próximo mês, a média da demanda diária dos três meses anteriores. Importantes exceções referem-se aos casos seguintes:

- produtos marcadamente sazonais, por exemplo, antigripais, loções protetoras, repelentes;

- promoções, freqüentes nos artigos de perfumaria e higiene pessoal;

- lançamentos de novos produtos, que chegam à casa de centenas anualmente. 
8. HADLEY, G., WHITIN, T. M. Analysis of inventory systems. Englewood Cliffs, N. J.: Prentice-Hall, 1963, p.152-3; BUFFA, Elwood S., MILLER, Jeffrey G. Production: inventory systems, planning and control. 3.ed. Homewood, III.: Richard D. Irwin, 1979. p.135; MONKS, Joseph G. Administração da Produção. São Paulo: McGraw-Hill, 1987. p.299, traduzido por Lauro Santos Blandy de Theory and Problems of Operations Management, 1985.
Conhecem-se técnicas para calcular o fator sazonal de um produto, que se reproduz de um ano a outro e permite reduzir a margem de subjetividade da previsão. Todavia, o banco de dados não possui sempre a capacidade de memória necessária para essa finalidade, e o pessoal de vendas confia mais no seu julgamento do que num frio número. Promoções e lançamentos serão bem-sucedidos se a previsão da demanda tiver sido efetuada com razoável margem de acerto e se venda e compra tiverem sido bem sincronizadas. Caso contrário, faltarão ou sobrarão produtos ao longo da cadeia de suprimentos, desde o fornecedor até a loja.

Além disso, há um considerável número de produtos cujo desvio-padrão é igual ou superior à sua média diária de vendas.

Recomenda-se dispor de bancos de dados potentes e aperfeiçoar a metodologia de previsão da demanda utilizada na empresa.

\section{Entrosamento entre os setores de vendas e compras}

Quando a rede de farmácias é organizada no formato tradicional, em departamentos separados de compras e vendas, os subsistemas de compras e de estoque do depósito central são monitorados pelo setor de compras enquanto o de vendas é comandado pela área comercial. Observa-se certo desencontro natural entre os dois subsistemas. $\mathrm{O}$ setor de compras deveria em princípio receber seus impulsos do setor de vendas, mas este último mostra dificuldades para prever a demanda, reagir às suas oscilações e transmitir as informações corretas e completas em tempo hábil à área de compras. $\mathrm{O}$ ingente número de produtos agrava os problemas.

Obstáculos de comunicação existem dentro da própria área comercial, entre diretoria, assessoria, gerências regionais e gerências de lojas. Notam-se também entraves na comunicação entre informática e os setores operacionais.

Esforços devem ser multiplicados no sen-

\section{Obtenção de informações gerenciais confiáveis}

Embora os conceitos de cobertura de estoque e nível de serviço sejam conhecidos da maioria dos executivos e a despeito dos esforços envidados para compilar as estatísticas desses indicadores, não é fácil uma rede de farmácias apresentar dados regulares, confiáveis e relevantes sobre giro do estoque e faltas de produtos. Os softwares não são montados para esse fim e os diversos setores da empresa, quando computam essas informações gerenciais, não obtêm resultados comparáveis. O setor de contabilidade tem sua maneira de calcular os estoques, o de vendas, outra, o de compras, uma terceira, e assim por diante. $\mathrm{O}$ índice de faltas de produtos, no depósito e nas lojas, apresenta problemas de conceituação e obtenção. A gravidade das faltas deveria ser mensurada pela margem de contribuição perdida, nos dias em que os estoques dos produtos estão zerados, ainda que esse cálculo seja trabalhoso.

\section{Rapidez na reposição dos produtos}

O estoque de segurança do depósito central e das lojas, que é mantido para se prevenir contra atrasos na reposição e flutuações da demanda, é função crescente dos prazos de entrega do fornecedor ao depósito e do depósito às lojas.

Se, por exemplo, forem necessários cinco dias para reabastecer a loja, o estoque de segurança da loja será cerca de $5 * * 0,5=2,24$ maior do que se o prazo de entrega fosse de um dia. A redução do tempo de entrega é uma forma eficiente de reduzir os estoques de segurança, que constituem parte apreciável dos estoques totais do depósito e das lojas. ${ }^{8}$

Compensa investir num sistema que não constitua um gargalo para o processamento rápido de substancial volume de dados. Para um mix de 5.000 itens e uma rede de 100 lojas, trata-se de processar diariamente 500.000 transações.

O reabastecimento diário da loja deve mentos, através de reuniões, formação de equipes interdepartamentais, seminários e reforço da liderança. Uma alternativa seria adotar um esquema de organização matricial, por linhas de produtos, comandadas por gerentes responsáveis pelas vendas e compras de sua categoria. ser efetuado repondo no dia $\mathrm{D}+1$ o que for necessário para o ressuprimento do estoque da loja em consequiência das vendas ocorridas no dia $\mathrm{D}$.

O reabastecimento diário, no depósito, de toda a gama de produtos, causaria na prática 
um aumento insustentável de serviço. No entanto, deve-se cogitar em efetuar reabastecimento bissemanal, negociando nesse sentido com os fornecedores.

\section{Coexistência de excessos e faltas de produtos}

É corriqueira a ocorrência simultânea de excessos de estoque e falta de produtos num sistema de varejo: alguns itens sobram em algumas lojas, outros faltam nestas e em outras lojas. Uma profusão das mais variadas causas - atrasos de um fornecedor, pane da computação, encalhe numa promoção, falha num lançamento - provoca consideráveis distúrbios na rede. Ainda que cada produto, individualmente, possua $99,99 \%$ de probabilidade de ser perfeitamente gerenciado, a probabilidade de não ocorrer nenhum excesso nem falta numa rede de 100 lojas, com um sortimento de 5.000 apresentações, é ínfima $\left(1,92 \times 10^{-22}\right)$. Recentemente, numa rede de 100 farmácias, observaram-se, no mesmo período, um estoque de 54 dias (10 no depósito e 44 nas lojas) e faltas de cerca de $10 \%$ dos itens da linha em algumas lojas relevantes.

Uma situação freqüente é a falta dos produtos de grande procura e a sobra dos itens de baixo giro. Da mesma forma, lojas de intenso movimento carregam menos de 20 dias de estoque, enquanto as menos ativas ostentam coberturas de 60 ou mais dias.

$\mathrm{Se}$, naquela rede, o estoque total fosse reduzido dos atuais 54 dias para factíveis 33 dias, a redução do estoque corresponderia a US\$ 9 milhões, e o principal benefício, proveniente da liberação do capital de giro, montaria a US\$ 3,2 milhões anuais. A redução das faltas pela metade, por sua vez, aumentaria a margem de contribuição em US\$ 2,7 milhões por ano. Para tanto, é necessário identificar e combater cada um da miríade de empecilhos que se antepõem à eficiência da gestão logística.

\section{Os produtos éticos de baixo giro}

Os produtos éticos de baixo giro comprometem os esforços de contenção do estoque. São cerca de 2.000 especialidades medicamentosas pouco receitadas. Seu preço é elevado. Por motivos sociais, algumas redes consideram ser sua obrigação manter uma ou duas unidades de cada um desses medicamentos em todas as suas lojas. Em farmácias típicas que adotam essa diretriz, verificou-se que esses itens contribuem com $45 \%$ a $75 \%$ do valor total do estoque de produtos farmacêuticos, o que levaria a concluir pela necessidade de se alterar a estratégia em foco.

Inexiste uma definição consensual do que vem a ser um produto de baixo giro. À guisa de ilustração, a Tabela 1 reproduz a terminologia empregada por uma rede (com pequenas adaptações nas classes e na nomenclatura, necessárias para maior clareza na exposição).

A venda de um produto de baixo giro pode ser considerada, estatisticamente, como um evento raro; sua demanda obedece à distribuição de Poisson e não à distribuição normal. Na primeira, ao contrário da última, o desvio-padrão é grande em relação à média, o que resulta numa dispersão considerável e, em conseqüência, numa cobertura elevada, conforme se pode verificar na Tabela 2.

Tabela 1 - Classificação dos produtos éticos de baixo giro utilizada numa rede de farmácias

\begin{tabular}{|c|c|c|}
\hline (1) & (2) & $(3) \cong 30 \times(2)$ \\
\hline Nomenclatura da classe & $\begin{array}{l}\text { Média diária de venda } \\
\text { na loja (em unidades) }\end{array}$ & $\begin{array}{c}\text { Média mensal de venda } \\
\text { na loja (em unidades) }\end{array}$ \\
\hline 1. Baixíssimo giro & até 0,009 & até 0,3 \\
\hline 2. Muito baixo giro & de 0,01 a 0,049 & de 0,3 a 1,5 \\
\hline 3. Baixo giro & de 0,05 a 0,12 & de 1,5 a 3,6 \\
\hline 4. Médio giro & de 0,12 a 1 & de 3,6 a 30 \\
\hline 5. Alto giro & acima de 1 & acima de 30 \\
\hline
\end{tabular}

Observação: pequenas adaptações foram efetuadas em relação à classificação usada pela rede. No texto, designamos como de baixo giro as categorias 1, 2 e 3. 
Na distribuição de Poisson, o desviopadrão é igual à raiz quadrada da demanda média. Se este for inferior a 1 , o desviopadrão torna-se proporcionalmente considerável, como se vê na coluna (4), e a cobertura do estoque, aproximadamente igual ao valor da coluna (5), avoluma-se.

A solução recomendável para a redução dos estoques dos produtos de baixo giro é mantê-los somente nas lojas de maior movimento, às quais os clientes que os procuram seriam referenciados. Uma alternativa é prometer entregá-los em poucas horas aos clientes, por meio de mensageiro que os retiram das lojas que os mantêm em estoque.

\section{Outros problemas de gestão}

Problemas adicionais enfrentados pelas redes de farmácias são mencionados a seguir:

- Redes que comercializam produtos farmacêuticos não registrados no Ministério da Saúde tendem a ser mais bem sucedidas do que as de estrita postura ética. A vigilância sanitária deveria ser mais atuante.

- Fórmulas corretas de gestão de estoque, que empregam o conceito de desviopadrão da demanda, são de processamento trabalhoso e demorado, mesmo por computadores modernos. Ademais, o pessoal de operação não as entende nem as aceita. Ou se expliquem essas fórmulas aos usuários, ou simplifiquem-nas, valendo-se de fórmulas aproximadas, ainda que menos corretas.

- O pessoal de vendas reclama de qualquer falta de produto nas lojas, mas não de excesso de estoque. A pressão exercida leva a autorizar os gerentes da loja a solicitar remessas extras, o que leva a prejudicar o bom funcionamento do sistema e a aumentar substancialmente os estoques.

- Nas redes em que inexiste um esquema de incentivo aos funcionários, não se deve esperar motivação para aumentar as vendas e reprimir a elevação excessiva dos estoques.

- É recomendável manter um sistema que permita a transferência dos produtos entre lojas, bem como o recolhimento dos medicamentos cujo prazo de validade se aproxima da expiração.

- A redução dos estoques dos produtos farmacêuticos libera espaço nas lojas, que deve ser preenchido por artigos de perfumaria e higiene pessoal, a fim de a loja não parecer vazia. Embora esses itens sejam mais baratos que os produtos éticos, o efeito final é o aumento desnecessário do estoque. Gôndolas e estantes abarrotadas são consideradas imprescindíveis para causar impacto visual no cliente.

- Uma sombra escurece as perspectivas do segmento: o "ticket" médio por cliente de farmácia em São Paulo é de apenas US\$ 12. Esse reduzido faturamento limita seriamente o pleno florescimento do setor.

\section{CONCLUSÃO}

O ramo de varejo farmacêutico realizou na última década consideráveis progressos de gestão, destacando-se a formação de redes, a utilização de aprimorados sistemas computadorizados de gestão de estoques em tempo real e a racionalização das operações de seu depósito central.

Apesar dos avanços obtidos, não se alcançam ainda o almejado just in time nem a desejada falta-zero e, muito menos, o Supply

Tabela 2 - Cobertura de estoque de produtos de baixo giro

\begin{tabular}{|l|l|l|l|l|}
\hline$(1)$ & $(2)$ & $(3) \sqrt{d}$ & $(4)=(3) /(2)$ & $(5)=2 \times(4)$ \\
\hline Categoria & $\begin{array}{l}\text { Demanda } \\
\text { diária média } \\
\text { d }\end{array}$ & $\begin{array}{l}\text { Desvio-padrão da } \\
\text { distribuição da } \\
\text { demanda diária } \\
\sigma\end{array}$ & $\begin{array}{l}\text { Coeficiente de } \\
\text { variação } \\
\sigma / d\end{array}$ & $\begin{array}{l}\text { Cobertura de } \\
\text { estoque } \\
2 \sigma / d\end{array}$ \\
\hline Baixíssimo giro & 0,009 & 0,095 & 10,5 & 21 \\
\hline Muito baixo giro & 0,05 & 0,224 & 4,5 & 9 \\
\hline Baixo giro & 0,12 & 0,346 & 2,9 & 5,8 \\
\hline Médio giro & 1 & 1 & 1,0 & 2 \\
\hline
\end{tabular}


Chain Management ou o Efficient Consumer Response, que pressupõem entrosamento entre fornecedor, farmácia e cliente final.

Antes de atingir esses ideais, há que se solucionar problemas organizacionais internos, de relacionamento e comunicação interdepartamentais, de treinamento de pessoal, de previsão de demanda e de capacidade computacional.

\section{APÊNDICE I}

\section{Quick Response - Pharmaceutical Distributor}

- Operando há mais de 70 anos no mercado suíço, a Galenica Distribution atende, atualmente, 10.000 itens (pico de 180.000) de pedidos por dia, percorrendo $22.000 \mathrm{~km}$ por dia, dispondo para tanto de 150 vans.

\section{- Possuindo ainda 9.000 sku, a Galenica,}

mediante a adoção e implantação das

observações feitas neste paper para o mercado nacional, atende às solicitações de reposição de produtos dos seus clientes em 12 horas.

- De posse de uma postura gerencial proativa e de operações integradas e sincronizadas, a Galenica passou de 30.000 itens manuseados por dia para 75.000 .

- Sem nem mesmo explorar o maior distribuidor de produtos farmacêuticos norte-americano

McKensson -, a resposta rápida, no caso da Galenica, permitiu-lhe obter preços mais competitivos, maior flexibilidade e disponibilidade de produtos.

Fonte: Business Advantage, Sweden, January 1998.

\section{APÊNDICE ॥}

\section{A indústria farmacêutica ${ }^{9}$}

\section{OS VITAMINADOS}

Quais são os dez maiores laboratórios do Brasil

\begin{tabular}{|c|c|}
\hline Laboratório & $\begin{array}{c}\text { Vendas/1997 - } \\
\text { em US\$ milhões }\end{array}$ \\
\hline Novartis & 1046,5 \\
\hline Hoechst Marion Roussel & 603,8 \\
\hline Aché & 504,7 \\
\hline Bristol-Myers Squibb & 485,0 \\
\hline Roche & 473,2 \\
\hline Boeringer Ingelheim & 363,1 \\
\hline Schering-Plough & 343,1 \\
\hline Sanofi & 268,1 \\
\hline Eli Lilly & 259,8 \\
\hline Glaxo Wellcome & 238,9 \\
\hline
\end{tabular}

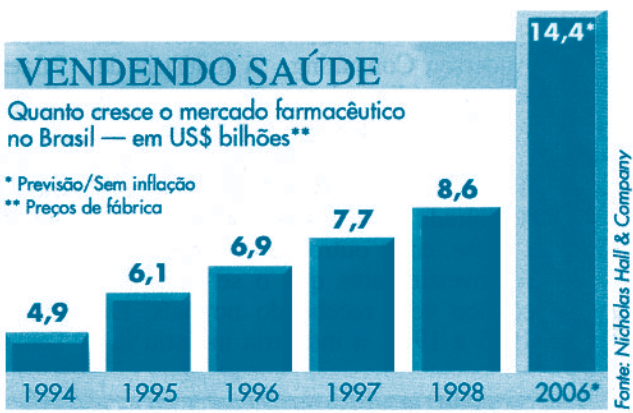

\section{DOSE ALTA}

As dez drogas que mais deram dinheiro no Brasil em 1997

\begin{tabular}{ll|l} 
Droga & \multicolumn{1}{|c}{$\begin{array}{c}\text { Laboratório } \\
\text { Cataflan }\end{array}$} & $\begin{array}{c}\text { Novartis } \\
\text { Faturamento- } \\
\text { em US\$ milhöes }\end{array}$ \\
\hline Keflex & Eli Lilly & 123 \\
\hline Capotem & Bristol-Myers Squibb & 93 \\
\hline Voltaren & Novartis & 76 \\
\hline Amoxil & Smithkline Beecham & 71 \\
\hline Renitec & Merck Sharp \& Dohme & 69 \\
\hline Novalgina & Hoechst Marion Roussel & 66 \\
\hline Lexotan & Roche & 59 \\
\hline Neosaldina & Knoll & 53 \\
\hline Tilenol & Janssen/Cilag & 48 \\
\hline
\end{tabular}

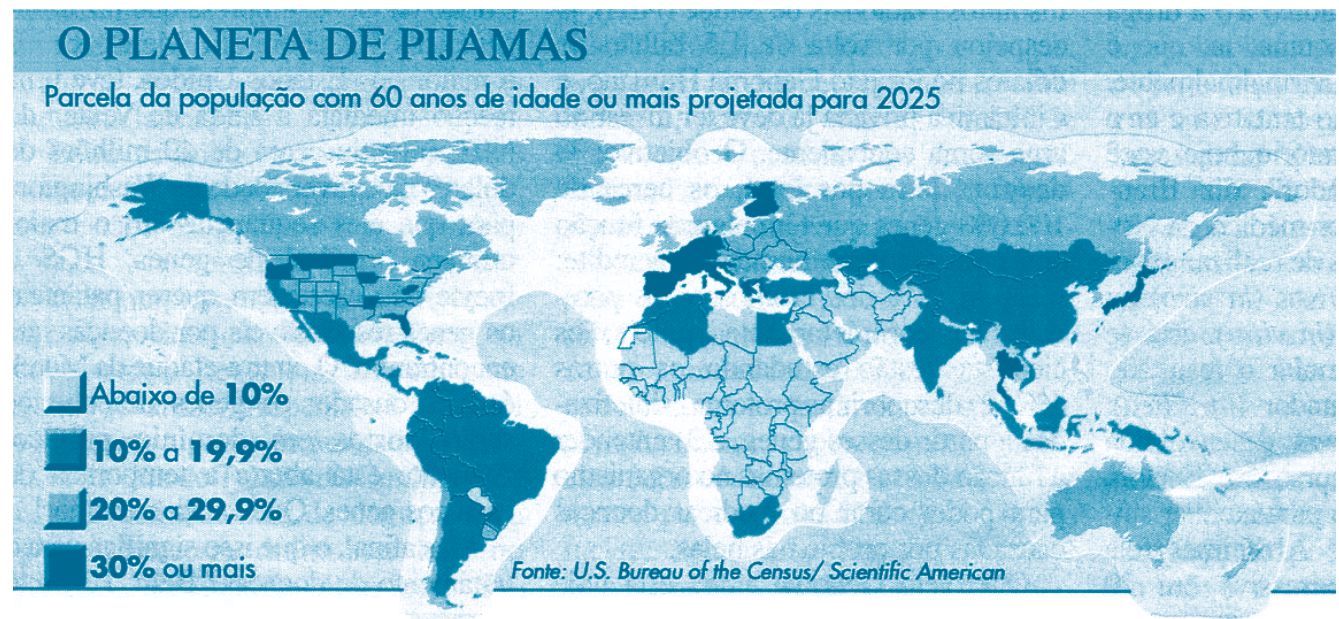

